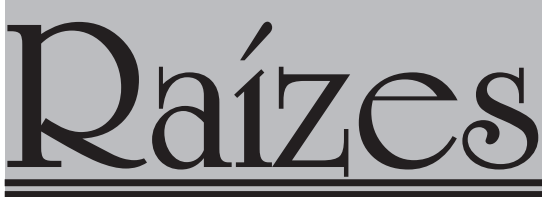

v.33, n.1, jan-jun /2013

\title{
ELEIÇÕES DEMOCRÁTICAS E TRANSFORMISMO POLÍTICO: PODER E DOMINAÇÃO POLÍTICA NO RIO GRANDE DO NORTE
}

\author{
João Emanuel Evangelista, Gustavo César de Macêdo Ribeiro
}

\begin{abstract}
RESUMO
Este artigo analisa os contornos assumidos pelas disputas eleitorais no Rio Grande do Norte. A polarização advinda dos tempos do regime militar entre os grupos clânico-oligarquicos liderados pelas famílias Alves e Maia no referido estado (agrupados partidariamente no PMDB e PFL/DEM, respectivamente) continua, após a redemocratização, a influenciar decisivamente a formação de alianças políticas, bem como as dinâmicas eleitorais no estado, no período 1994-2010. Nos anos 2000, num típico caso de transformismo político, conforme a elaboração gramsciana, Wilma de Faria (PSB), originária dos grupos políticos tradicionais, desponta no cenário político com uma vitória para o governo do estado. Entre disputas internas e arregimentação de grupos políticos secundários (que vão desde grupos familiares com influência no interior do estado aos partidos de esquerda, como o PT), esses três grupos monopolizam a cena política, mantendo no estado um padrão bipolar de disputa eleitoral.
\end{abstract}

Palavras-chave: Política; Eleições; Hegemonia; Transformismo; Oligarquias

\section{DEMOCRATIC ELECTIONS AND POLITICAL TRANSFORMISM: POLITICAL DOMINA- TION AT RIO GRANDE DO NORTE STATE}

\begin{abstract}
This article examines the contours assumed by the elections disputes at the Rio Grande do Norte State. The polarization between the groups clan-oligarchic led by the Families Alves and Maia in the referred state (grouped adherently at the PMDB and PFL/DEM parties, respectively), arising from the times of Military Regime, continues after the redemocratization to influence decisively the formation of political aliances, as well the electoral dynamics at the State, at the period from1994 to 2010. At the 2000's, in a typical case of political transformism, according to Gramsci's political theory, Wilma de Faria (PSB), originating from traditional groups, emerges on the political scene with a victory for the state government. Between infighting and regimentation of secondary political groups (that includes other familiar groups in the countryside of the state and Left Parties, as the PT), this three groups monopolize the political scene, keeping a bipolar pattern of electoral dispute.
\end{abstract}

Key words: Politics; Elections; Hegemony; Transformism and Oligarchies

Professor do Programa de Pós-Graduação em Ciências Sociais da Universidade Federal do Rio Grande do Norte (PPGCS/UFRN). E-mail: joao.e.evangelista@gmail.com.

Doutorando do Programa de Pós-Graduação em Ciências Sociais (PPGCS/UFRN). E-mail: gustavo.cmr@gmail.com 


\section{INTRODUÇÃO}

A modernização capitalista no Brasil seguiu uma lógica histórica retardatária em relação aos países capitalistas centrais. Houve, durante muitas décadas do século XX, o predomínio inconteste da sociedade política sobre a sociedade civil, cujo fortalecimento também foi muito lento e tardio. Somente depois do expressivo desenvolvimento capitalista e intenso processo de urbanização, ocorrido a partir do governo Kubichek e, em especial, durante o regime militar, surgiu uma sociedade civil diversificada e complexa, criando um novo equilíbrio nas relações entre a sociedade política e a sociedade civil na composição do Estado ampliado brasileiro (Gramsci, 2000; Coutinho, 1999). Isso ocorreu, sobretudo, nas unidades federativas mais desenvolvidas que atuam como polos dinâmicos da modernização capitalista, como São Paulo, Rio de Janeiro, Minas Gerais e Rio Grande do Sul. Esse fenômeno não foi homogêneo na sociedade brasileira. Nas regiões periféricas, como as unidades federativas nordestinas, com exceção de alguns estados com tradição histórica de grandes lutas e movimentos sociais, caso de Pernambuco, continuou a imperar uma forte assimetria entre a sociedade política e a sociedade civil, com a centralidade da sociedade política.

Essa relação assimétrica entre um Estado forte e hipertrofiado e uma sociedade civil frágil e gelatinosa produziram um deslocamento das lutas e conflitos da sociedade civil para o interior do Estado no sentido estrito, que desempenha o papel de centro impulsionador de mudanças políticas e socioeconômicas. Com isso, as disputas políticas entre os diferentes segmen- tos das classes dominantes são concentradas na luta pelo controle dos aparatos governamentais e da burocracia do Estado brasileiro, que se torna o palco privilegiado dos conflitos e das contradições em torno do acesso aos fundos públicos, da definição de políticas públicas e da distribuição da riqueza social produzida. Esse cenário sociopolítico é muito apropriado para a reprodução da tradição patrimonialista nas relações entre o Estado e a sociedade civil na sociedade brasileira (Evangelista, 2006b, p. 4).

As transformações ocorridas na sociedade brasileira como consequência necessária da modernização capitalista tomou a forma de revolução passiva, com a generalização da prática política do transformismo pelas classes e seus grupos político-partidários dominantes. No Brasil, as contradições sociais e os conflitos políticos engendrados no processo histórico são sempre adiados e nunca são superados; ao contrário, as posições que representam o velho e o novo e o moderno e o arcaico encontram numa monótona reiteração em formas heteróclitas de combinação e acomodação. A "conciliação pelo alto" entre os grupos políticos dominantes e a incorporação e cooptação transformistas dos grupos subalternos e dos movimentos potencialmente transformadores são estratégias complementares que predominam nos momentos históricos decisivos (Coutinho, 1988; Gramsci, 2002; Vianna, 1997). Assim, o bloco hegemônico é composto por grupos político-partidários que podem se revezar no governo e na oposição e disputar nos processos eleitorais a condição de grupo político governante. A hegemonia é exercida por diversos grupos e alianças político-partidários que objetivam o controle do governo nos diferentes níveis. Não há 
diferenças substanciais de visão de mundo entre esses diferentes grupos político-partidários que constituem o bloco hegemônico, que tanto podem ser adversários como aliados políticos nas eleições realizadas em diferentes momentos e processos eleitorais.

\section{A TRADIÇÃO HISTÓRICA DA BIPOLARI- ZAÇÃO POLÍTICA E ELEITORAL}

A política norte-rio-grandense possui uma longa tradição histórica de bipolarização entre duas grandes lideranças e seus respectivos grupos políticos que competem para dirigir a sociedade e comandar o governo e o aparelho de Estado em aliança com lideranças políticas secundárias ou auxiliares. Nos anos 1960 e 1970, as disputas políticas ocorriam entre o dinartismo, liderado por Dinarte Mariz, e o aluizismo, comandado por Aluízio Alves, abrigados no início em facções dentro da antiga ARENA - "ARENA Vermelha" e "ARENA Verde" e, depois, no PDS e no MDB, respectivamente. Nos anos 1980 e 1990, a competição se dava entre o "maismo, liderado por Tarcísio Maia, Lavoisier Maia e José Agripino Maia no PDS e, depois", PFL, e o "aluizismo", comandado por Aluízio Alves, Henrique Alves e Garibaldi Alves Filho no MDB e, depois, PMDB. Ao longo do tempo, a família Rosado, que comanda tradicionalmente a política em Mossoró, segunda maior cidade, dividiu-se em duas facções políticas que estabelecem alianças com os dois grupos oligárquicos dominantes que ocupam a condição de governo e de oposição (Evangelista, 2006a).
Com a redemocratização do país e a consolidação da democracia eleitoral e do multipartidarismo, as polarizações entre dois blocos político-partidários, que obedecem a uma lógica clânico-oligárquica, incorporaram novos atores políticos e sociais, que adquiriram maior complexidade e diversidade. Além disso, os clãs políticos Maia e Alves sofreram divisões internas, com importantes consequências para o rearranjo das forças políticas no cenário estadual. Neste processo, uma "terceira força" surge e consolida-se: a liderança de Wilma de Faria ${ }^{1}$. Contudo, mesmo com sua ascensão, a dinâmica do sistema político estadual manteve-se condicionada pela competição e movimentação, num padrão bipolar, entre três grupos político-partidários principais - José Agripino Maia/DEM, Garibaldi Filho/Henrique Alves/PMDB e a própria Wilma de Faria/PSB que se alternam no comando do aparelho governamental como governo e como oposição e estabelecem entre si alianças pendulares.

O senador José Agripino Maia é filho e herdeiro político do ex-governador Tarcísio Maia (1975-1978), que foi indicado de forma indireta para o cargo com o apoio do então senador Dinarte Mariz (ARENA/PDS), de quem havia sido Secretário de Educação em seu governo no período de 1955 a 1960. Nesse início da sua carreira política, Tarcísio Maia elegeu-se deputado federal pela UDN (1959-1963) com atuação pouco expressiva. José Agripino ingressou na política como prefeito indicado de Natal, em 1979, por seu primo e também governador indireto Lavoisier Maia (1979-1982). Fazia parte da geração de jovens prefeitos das capitais nordestinas, com formação profissio-

1 Primeiro filiada ao PDT, consolida sua figura pública filiada ao PSB, partido que ajuda a expandir no plano estadual. 
nal universitária e perfil tecnocrático, que foram indicados para os cargos pelo governo militar num esforço de renovação de suas lideranças no Nordeste. Na prefeitura, construiu sua liderança política promovendo a expansão habitacional e a modernização urbana de Natal, através do incentivo e apoio ao desenvolvimento do turismo e construção de avenidas e conjuntos habitacionais em bairros populares periféricos. Em 1982, na primeira eleição direta para os governos estaduais depois do golpe civilmilitar de 1964, candidato pelo PDS, foi eleito governador (1983-1986) vencendo a mitológica liderança do ex-governador Aluízio Alves (1961-1966).

Depois disso, disputou todas as eleições e tornou-se uma das mais importantes lideranças políticas do Rio Grande do Norte. Nas eleições de 1986, foi eleito senador; nas eleições de 1990, foi eleito governador (1991-1994) pela segunda vez. Nas eleições de 1994 elegeuse novamente senador e renovou seu mandato senatorial nas eleições de 2002 e 2010. Contudo, foi candidato derrotado a governador nas eleições de 1998, com o apoio do PSB de Wilma de Faria, quando perdeu para Garibaldi Alves Filho, que foi reeleito. Nos últimos anos, tornou-se uma das mais importantes lideranças nacionais do antigo PFL e do atual DEM, que dirige o bloco liberal-conservador em aliança orgânica com o PSDB e o PPS, com destacada atuação no Congresso Nacional em apoio e sustentação ao Governo do Presidente Fernando Henrique Cardoso e de oposição sistemática ao Governo do Presidente Luiz Inácio Lula da Silva e da Presidenta Dilma Rousseff.
$\mathrm{O}$ antigo "aluizismo", que se trasmutou em "alvismo", identifica-se com o PMDB no Rio Grande do Norte. Com o passar dos anos, as limitações de saúde trazidas pela idade avançada impôs a transferência da liderança de Aluízio Alves ${ }^{2}$ para Henrique Alves, seu filho, e Garibaldi Alves Filho, seu sobrinho. Essa liderança compartilhada nem sempre é exercida sem conflitos, provocados por eventuais divergências entre os interesses políticos de Garibaldi e de Henrique, o que leva o PMDB a uma situação de ambiguidade e/ou de paralisia em certos contextos eleitorais. Apesar do desejo e dos esforços de Aluízio Alves, Henrique Alves não conseguiu, até agora, ocupar nenhum cargo executivo. Em 1988, foi candidato do PMDB à sucessão de Garibaldi Alves Filho à Prefeitura de Natal, sendo derrotado por Wilma de Faria (que à época ainda era Wilma Maia, pois era esposa de Lavoisier Maia). Em 1992, foi candidato, mais uma vez, a prefeito de Natal e perdeu, no segundo turno, para o desconhecido Aldo Tinoco, engenheiro sanitarista, apoiado por Wilma de Faria. No segundo mandato como governador de Garibaldi Alves Filho, mais uma vez fracassou a estratégia de capacitar Henrique Alves para disputar com chances de vitória a sucessão estadual em 2002. Em contrapartida, Henrique Alves possui uma trajetória política marcada por votações expressivas na renovação consecutiva do seu mandato de deputado federal desde 1970, sobressaindo-se sempre como um dos deputados federais mais votados na bancada potiguar. Tornou-se uma das principais lideranças e articuladores políticos do PMDB na Câmara dos Deputados.

2 Aluízio Alves faleceu em maio de 2006. 
Por sua vez, a trajetória política de Garibaldi Alves Filho começou com sua eleição para a Assembleia Legislativa em 1970 pelo antigo MDB. Depois de quatro mandatos como um dos deputados estaduais mais votados, Garibaldi Filho derrotou Wilma de Faria - à época Wilma Maia -, representante do grupo Maia, sendo eleito prefeito de Natal em 1985, na primeira eleição direta para as capitais brasileiras depois do golpe militar de 1964. A candidatura de Garibaldi Filho representava a ampla aliança das forças políticas que estiveram à frente da resistência democrática durante o regime autoritário. Nestas eleições, o grupo Alves recuperou seu prestígio e força política, depois da estonteante derrota sofrida por Aluízio Alves, pelo PMDB, no confronto com o jovem José Agripino Maia, pelo PDS, nas eleições para governador em 1982. Depois do mandato de prefeito da capital, foi eleito senador em 1990 e em 1994 foi eleito no primeiro turno como governador do Rio Grande do Norte, com 52,7\% dos votos, derrotando Lavoisier Maia (PDT), 38,7\% dos votos, que teve o apoio de José Agripino (PFL). Em 1998, foi reeleito governador com 50,2\% dos votos no primeiro turno, vencendo José Agripino (PFL), que obtém 41,3\% dos votos. Deixou o governo para concorrer e ser eleito ao senado nas eleições de 2002.

Amargou sua primeira derrota eleitoral ao perder, no segundo turno, as eleições para o governo estadual em 2006 para Wilma de Faria, reeleita governadora do Rio Grande do Norte ${ }^{3}$. Apesar de derrotado, Garibaldi Filho confirmou sua liderança política com vitória eleitoral nas maiores cidades da região metropolitana de
Natal: perdeu em Natal ( $1^{\circ}$ turno: $43,3 \%, 2^{\circ}$ turno: 47,5\%), mas venceu em Parnamirim $\left(1^{\circ}\right.$ turno: 54,1\%, $2^{\circ}$ turno: 56,6\%), em São Gonçalo do Amarante ( $1^{\circ}$ turno: $52,8 \%, 2^{\circ}$ turno: $54,7 \%$ ) e em Macaíba (10 turno: 56,3\%, $2^{\circ}$ turno: 57,9\%). Em 2010, em aliança com José Agripino, com a estratégia do "voto casado", foi reeleito como o senador mais votado (TSE).

Em mais uma dessas ironias da história, José Agripino, o algoz do patriarca Aluízio Alves em 1982, tem conseguido sobreviver ao declínio nacional do DEM através do apoio ativo de Garibaldi Filho nos últimos processos eleitorais. Num olhar retrospectivo sobre a política potiguar, uma das "novidades" mais recentes é a reiterada aliança político-eleitoral estabelecida entre Garibaldi Filho (PMDB) e José Agripino (DEM).

\section{O SURGIMENTO DE UMA “TERCEIRA FORÇA"}

Wilma de Faria lidera, no PSB, o terceiro grande grupo político-partidário estadual. Trata-se de um caso típico de renovação política transformista num contexto de dominação clânico-oligárquica, em que uma liderança com origem no grupo Maia, que surgiu como base de apoio ao regime militar, operou uma transmutação ao migrar para partidos políticos que nacionalmente se situam no espectro de centro-esquerda e de esquerda. Ao mesmo tempo, atua com um discurso de esquerda e reproduz práticas e valores políticos conservadores tradicionais - como, por exemplo, o personalismo, o fa- 
milismo, o clientelismo e o assistencialismo ${ }^{4}-$, ocupando o espaço político da esquerda local.

Seu ingresso na política decorreu dos seus vínculos familiares com o grupo Maia, na condição de esposa do governador indireto Lavoisier Maia ${ }^{5}$, organizando as ações de assistência social do governo estadual. No governo de José Agripino, eleito em 1982, assumiu a Secretaria de Trabalho e Ação Social, dando continuidade ao assistencialismo oficial com grande foco em Natal. Suas relações com as comunidades dos novos conjuntos habitacionais nos bairros periféricos foram suas credenciais para concorrer à Prefeitura de Natal nas eleições de 1985, perdendo para Garibaldi Alves Filho (PMDB), que era apoiado por uma aliança de forças democráticas liberais e de esquerda.

Eleita para o Congresso Constituinte, em 1986, teve destacada atuação e se aproximou da agenda e das propostas defendidas pela esquerda. Depois disso, apropriou-se da legenda do PDT, forçando a saída de militantes trabalhistas históricos, sendo eleita prefeita de Natal em 1988 ao derrotar a candidatura de Henrique Alves (PMDB), numa aliança com José Agripino (PFL), que tem Ney Lopes (PDS) como vice-prefeito. Depois disso, trocou novamente de filiação partidária e passou a controlar o PSB, mais uma vez tomando para suas mãos uma legenda de esquerda de militantes socialistas.
Como uma liderança emergente, elegeu como prefeito de Natal Aldo Tinoco (PSB), engenheiro sanitarista que era seu colaborador no secretariado municipal, em 1992, derrotando no segundo turno Henrique Alves (PMDB), que pretendia ser o principal herdeiro do aluizismo. Rompeu com Aldo Tinoco e candidatouse novamente à eleição para Prefeitura de Natal em 1996, com o apoio de José Agripino. Nessas eleições enfrentou com sucesso a surpreendente candidatura da então deputada estadual Fátima Bezerra (PT) no segundo turno, numa campanha histórica disputadíssima - Wilma de Faria (PSB), com 51,7\% dos votos e Fátima Bezerra (PT), com 48,3\% dos votos -, que transformou, pela primeira vez, o PT na principal força competitiva da esquerda na política local (TSE, 1996).

Em 2000, com o apoio do governador Garibaldi Alves (PMDB), candidatou-se e foi reeleita como prefeita de Natal com 57,7\% dos votos, enfrentando Fátima Bezerra (PT) - 29,4\% dos votos - e Sonali Rosado (PFL), candidata de José Agripino, que obteve apenas 11,0\% (TSE, 2000). Renunciou à prefeitura, sendo substituída pelo vice-prefeito Carlos Eduardo Alves (PSB), para concorrer às eleições para governador em $2002^{6}$. No segundo turno, venceu o candidato Fernando Frei-

4 Há, inclusive, graves acusações de práticas de corrupção, com a investigação da Polícia Federal, na Operação Hígia, sobre o envolvimento do advogado Lauro Maia, filho da ex-governadora Wilma de Faria (PSB) e do deputado estadual Lavoisier Maia (PSB). Ele é acusado de tráfico de influência na Secretaria Estadual de Saúde. Em junho de 2008, chegou a ser preso, juntamente com outros 12 investigados, pela Polícia Federal (HÍGIA, Nominuto - http:/www.nominuto.com/noticias/politica/higia-lauro-diz-que-acusacoes-sao-tentativa-de-atingir-wilma-de-faria/52203). A Operação Hígia apura fraudes em licitações e contratos superfaturados na Secretária Estadual da Saúde, durante o governo de Wilma. Suspeita-se também que esse seria um dos mecanismos de financiamento ilegal de campanha do grupo política da ex-governadora Wilma de Faria.

5 Foi o último governador indicado, nomeado em 1978, durante o regime militar.

6 Nas eleições de 2002, no primeiro turno, Wilma de Faria (PSB) foi a mais votada com 37,6\% dos votos, seguida por Fernando Freire (PMDB) com 30,9\% dos votos e, em terceiro lugar, por Fernando Bezerra (PTB) com 19,9\% dos votos (TSE, 2002). 
re (PMDB), vice-governador apoiado por Garibaldi Filho, tendo o apoio de José Agripino (PFL) e do PT ${ }^{7}$ : Wilma de Faria obteve 61,05\% e Fernando Freire alcançou 38,95\% dos votos.

Em 2006, numa eleição muito disputada, Wilma de Faria enfrentou a forte liderança de Garibaldi Filho, considerado favorito no início da campanha eleitoral. No primeiro turno, a então candidata postulante à reeleição conseguiu 49,6\% e Garibaldi, 48,6\% dos votos; no segundo turno, venceu a eleição com uma pequena ampliação da sua maioria eleitoral - alcançando 52,38\%, contra 47,62\% de seu opositor. Nessas eleições, Wilma de Faria (PSB) foi reeleita governadora, em aliança com o PT, derrotando Garibaldi Filho (PMDB), que estava aliado com José Agripino (PFL).

Contudo, no auge da sua trajetória política, quando foi reeleita governadora do Rio Grande do Norte em 2006, surgiram os primeiros sinais de declínio da sua liderança política em Natal e na região metropolitana de Natal. O seu desafiante, Garibaldi Filho, ganhou nos dois turnos da eleição na região metropolitana, enquanto Wilma de Faria ganhou somente em Natal, mesmo assim com uma diferença relativa que diminuiu no segundo turno ${ }^{8}$. Além disso, nessa eleição, o candidato apoiado por Wil- ma de Faria ao senado que tentava a reeleição, Fernando Bezerra (PTB), foi derrotado em Natal por Rosalba Ciarlini Rosado (PFL), ex-prefeita de Mossoró, candidata apoiada por Garibaldi Filho e José Agripino9 Finalmente, em 2010, renunciou ao governo do Estado para candidatar-se sem sucesso ao Senado, sendo derrotada com a recondução dos mandatos senatoriais de Garibaldi Filho (PMDB) e de José Agripino (DEM), que se mantiveram aliados nas últimas disputas políticas locais.

\section{AS FORÇAS POLÍTICAS AUXILIARES}

Ao lado desses três principais conglomerados político-partidários, há grupos auxiliares, que estabelecem alianças com os grupos político-partidários principais em arranjos diferentes em cada processo eleitoral.

Dentre estas forças políticas, destaca-se a família Rosado, com base eleitoral em Mossoró e cidades circunvizinhas da região Oeste, que ocupa continuamente 2 vagas $(25 \%)$ da representação política potiguar na Câmara dos Deputados há mais de 50 anos, sendo constituída por duas facções da família Rosado, hoje abrigadas no DEM e no PSB.

7 No primeiro turno, o PFL apoiou Fernando Bezerra (PTB), numa coligação entre PTB, PFL, PPS, PV, PAN e PSL, que obteve 261.225 votos (19,9\%); e o PT lançou a candidatura de Ruy Pereira (PT), que alcançou 147.380 votos (11,2\%), numa coligação entre PT, PcdoB, PMN e PL (TSE, 2002).

8 O resultado eleitoral, em 2006, foi o seguinte em termos relativos da preferência dos eleitores. No primeiro turno: Natal - Wilma 52,3\% e Garibaldi 43,3\%; Parnamirim - Wilma 42,4\% e Garibaldi 54,1\%; São Gonçalo do Amarante - Wilma 44,9\% e Garibaldi 52,8\%; e Macaíba - Wilma 42,4\% e Garibaldi 56,3\%. No segundo turno: Natal - Wilma 52,4\% e Garibaldi 47,5\%; Parnamirim - Wilma 43,3\% e Garibaldi 56,6\%; São Gonçalo do Amarante - Wilma 45,3\% e Garibaldi 54,7\%; e Macaíba - Wilma 42,0\% e Garibaldi 57,9\% (TSE, 2006).

9 No Rio Grande do Norte, numa eleição com três candidatos competitivos, a ex-prefeita de Mossoró Rosalba Ciarlini (PFL) obteve 44,18\% dos votos; o senador Fernando Bezerra (PTB), 43,42\% dos votos; e o ex-governador Geraldo Melo (PSDB), 10,64\% dos votos. Em Natal, foi esse o resultado eleitoral: Rosalba Ciarlini com 41,99\% dos votos, Fernando Bezerra com 40,28\% dos votos e Geraldo Melo com 12,98\% dos votos (TSE, 2006). 
Sobressai-se, também, algumas lideranças emergentes, como o atual vice-governador Robinson Faria, que controlava o PMN e recentemente passou a comandar o PSD no Rio Grande do Norte, possuindo base eleitoral concentrada na região metropolitana de Natal e na região Agreste do Rio Grande do Norte; o deputado federal João Maia, que controla o PR, tendo base eleitoral principalmente na região metropolitana de Natal e na região do Seridó do Rio Grande do Norte; o prefeito Carlos Eduardo Alves, atualmente no comando do PDT, com forte presença eleitoral em Natal e também em algumas cidades da região metropolitana de Natal; e o ex-deputado federal Rogério Marinho ${ }^{10}$, que controla atualmente o PS$\mathrm{DB}$, e tem sua principal base eleitoral na região metropolitana de Natal.

As lideranças intermediárias precisam ter o controle de máquinas partidárias de pequenos e médios partidos como forma de assegurar um mínimo de autonomia para aumentar seu poder de barganha nas alianças com os grupos político-partidários principais, como são o caso, por exemplo, de Robinson Faria com o PMN e o PSD, de João Maia com o PR e de Carlos Eduardo com o PDT. Essas lideranças políticas não podem abrir mão de ter o controle das máquinas partidárias, para viabilizar seus projetos políticos pessoais.
Outro fenômeno recorrente na política potiguar é a acomodação de um grupo de deputados estaduais numa determinada sigla partidária que atua como forma de aumentar o seu poder de barganha para obter acesso a recursos políticos para a reprodução da sua base político-eleitoral - sobretudo, cargos e investimentos locais - em troca do apoio necessário à sustentação parlamentar dos sucessivos governos estaduais. Foi assim no passado recente com o PL e com o PMN. É assim com o PROS, que foi criado, em 2013, no Rio Grande do Norte, sob a liderança do deputado estadual Ricardo Motta, presidente da Assembléia Legislativa, com a participação de cinco deputados estaduais ${ }^{11}$.

Na esquerda, o PT e o PCdoB são as duas forças político-partidárias com maior expressão eleitoral. O PCdoB foi um aliado do projeto político de Wilma de Faria (PSB) durante seus mandatos enquanto governadora do estado. O PT, premido pela política nacional de alianças, oscilou entre a independência e o apoio político aos governos do PSB no Rio Grande do Norte.

O PT representa o maior partido da esquerda potiguar, apesar da persistente dificuldade para ampliar sua base eleitoral e superar o trauma de origem de luta interna entre lideranças de correntes-partidos que paralisam a ação partidária e impedem o surgimento de

10 Rogério Marinho é uma liderança política em declínio. Atualmente é secretário de Desenvolvimento Econômico do governo Rosalba Ciarlini. Despontou no cenário político atuando no PSB. Com o apoio de Wilma de Faria e dos recursos políticos da máquina governamental, elegeu-se vereador em 2004, ocupando a presidente da Câmara Municipal de Natal, e, depois, deputado federal em 2006. No período que antecedeu as eleições para prefeito de Natal em 2008, insurgiu-se contra a liderança de Wilma de Faria, que defendia uma candidatura de unidade da chamada base aliada do governo Lula à prefeitura de Natal. Seu projeto era ser candidato do PSB a prefeito de Natal. Perdeu a indicação na convenção eleitoral do PSB de Natal. Depois disso, ingressou no PSDB e comanda o seu diretório estadual. Conseguiu uma suplência de deputado federal na eleição de 2010. Foi candidato a prefeito de Natal em 2012, ficando em quarto lugar, com 38.575 votos (10,2\%).

11 No Rio Grande do Norte, o PROS é presidido pelo deputado estadual Ricardo Motta, presidente da Assembléia Legislativa, que era filiado ao PMN, e pelos deputados estaduais Gilson Moura (ex-PV), Gustavo Carvalho (ex-PSB), Raimundo Fernandes (ex-PMN) e Vivaldo Costa (ex-PR). 
um projeto político alternativo para a sociedade norte-rio-grandense. O PT local não conseguiu seguir a trajetória nacional do PT e seu desempenho político-eleitoral em outros estados do Nordeste, transformando-se em partido de massas com vocação para chegar ao poder e dirigir a sociedade.

$\mathrm{Na}$ ausência de um projeto político partidário, predominam os interesses e os projetos políticos das lideranças dos grupos políticos internos, numa aproximação da lógica geral de prevalência dos interesses de ascensão e sobrevivência política de lideranças individuais nos partidos políticos brasileiros. Mesmo assim, o PT tem mantido a representação política mínima de 01 deputado estadual na Assembleia Legislativa ${ }^{12}$ e 01 deputado federal na Câmara dos Deputados.

$\mathrm{Na}$ trajetória petista, destaca-se a liderança da deputada federal Fátima Bezerra, que foi candidata sem sucesso à Prefeitura de Natal em quatro eleições consecutivas - de 1996 a 2008 - e tem demonstrado grande desempenho nas eleições para a Câmara dos Deputados, sendo reconduzida para seu terceiro mandato como a deputada federal mais votada, com 220.335 votos, em 2010 (TSE, 2010). Apesar de contradição aparente, as derrotas eleitorais em Natal criaram condições sinérgicas para a consolidação da imagem pública e da liderança de Fátima Bezerra, que tem destacada atuação parlamentar na Câmara dos Deputados ${ }^{13}$.

$\mathrm{Na}$ eleição para a prefeitura de Natal em 2012, o deputado estadual Fernando Mineiro (PT) fez uma campanha eleitoral em que se diferenciou dos demais candidatos por apresentar diagnósticos e propostas de solução para os problemas da população natalense. O caráter propositivo da sua campanha configurou um contraponto à monótona polarização promovida pelo marketing eleitoral de Carlos Eduardo (PDT) e de Hermano Moraes (PMDB). Além disso, destacou-se como um candidato que apresentou um programa de governo qualificado nos debates promovidos pelas diversas emissoras de televisão. Com isso, sua candidatura teve um grande crescimento na reta final da campanha e por muito pouco não foi para o segundo turno das eleições para disputar a Prefeitura de Natal com Carlos Eduardo Alves (PDT). No primeiro turno, Carlos Eduardo (PDT) obteve 153.464 votos (40,4\%); Hermano Moraes (PMDB), 87.380 votos (23,0\%); e Fernando Mineiro (PT), 85.915 votos $(22,6 \%)^{14}$.

12 A eleição de 2002 constituiu uma exceção a isso, pois o PT elegeu dois deputados estaduais: Paulo Davim e Fernando Mineiro (TSE, 2002).

13 Em 1996, em seu melhor desempenho eleitoral para a Prefeitura de Natal, numa eleição muito competitiva: Wilma de Faria (PSB) obteve 35,79\% dos votos, seguida por Fátima Bezerra (PT) com 28,88\% dos votos e João Faustino (PSDB) com 25,69\% dos votos; no segundo turno, Wilma de Faria vence a eleição com 51,68\% dos votos contra 48,32\% de votos para Fátima Bezerra (TSE, 1996). Em 2000, perde novamente para Wilma de Faria, agora no primeiro turno, alcançando $29,3 \%$ dos votos e ficando na segunda colocação. Em 2004, em seu pior desempenho eleitoral, fica em quarto lugar com apenas 7,4\%, numa eleição em que Carlos Eduardo Alves (PSB) vence Luiz Almir (PSDB) no segundo turno. E, finalmente, na última eleição municipal em 2008, finalizada no primeiro turno, Fátima Bezerra, com o apoio de Wilma de Faria (PSB), Garibaldi Filho e Henrique Alves (PMDB), atinge 36,8\% dos votos e perde para Micarla de Sousa, que alcança 50,8\% dos votos, com o apoio do senador José Agripino (DEM), da senadora Rosalba Ciarlini (DEM), do deputado federal João Maia (PR) e do deputado federal Rogério Marinho (PSDB) e do deputado estadual Robinson Faria (PMN).

14 No segundo turno, Carlos Eduardo (PDT) foi eleito Prefeito de Natal, com 214.687 votos (58,3\%), contra Hermano Moraes (PMDB), com 153.522 votos (41,7\%). Dados disponíveis no TSE (2012). 
Tal pleito, ademais, marcou uma reorganização do grupo liderado pelo PSB de Wilma de Faria: além do cisão do PT, com a candidatura de Fernando Mineiro, a ex-governadora voltou ao executivo municipal de Natal como vice-prefeita eleita na chapa de Carlos Eduardo.

Na eleição municipal em 2012, surgiram também novos atores de esquerda na representação parlamentar da Câmara Municipal de Natal. Nessa eleição, aconteceu um fenômeno político inusitado. Em decorrência da exposição de vídeo nas novas redes sociais na internet $\mathrm{e}$ sua repercussão em programa nacional de televisão ${ }^{15}$, Amanda Gurgel, professora da rede pública estadual, tornou-se a grande estrela das eleições em Natal. Amanda Gurgel (PSTU) foi a vereadora mais votada, ultrapassando as fronteiras sociais e geográficas das zonas eleitorais de $\mathrm{Na}$ tal. Alcançou 32.819 (8,6\%) votos, fato inédito na história política de Natal e do Rio Grande do Norte. Com essa votação excepcional, possibilitou a eleição de dois vereadores do PSOL, Sandro Pimentel, com 1.398 votos, e Marcos Ferreira, com 717 votos, através do quociente eleitoral obtido pela coligação partidária firmada entre o PSTU e o PSOL (TSE, 2012).

\section{O ESGOTAMENTO HISTÓRICO DAS LI- DERANÇAS TRADICIONAIS?}

Essa visão panorâmica do cenário político estadual, com a apresentação dos seus grupos político-partidários constitutivos, também evidencia que as principais lideranças políticas ocupam o lugar de protagonismo no posicio- namento e na articulação das coligações eleitorais há mais de 40 anos. Ingressam na política na década de 1970 e 1980. Para evitar o esgotamento histórico desse sistema político clânico-oligárquico, nos processos eleitorais mais recentes, há evidências de uma tentativa de renovação dos principais grupos político-partidários, através da entrada em cena de novos personagens do sempre igual enredo político.

Os partidos políticos brasileiros possuem algumas características que lhes são peculiares. A grande maioria dos nossos partidos políticos não dispõe de uma burocracia profissional que é indispensável para a disputa e a conquista de votos numa democracia eleitoral em ampliação constante (SANTOS, 2003). Isso requer que se estabeleçam vínculos de confiança e dependência mútuas entre os líderes e a máquina partidária nas sociedades modernas (WEBER, 1999), com a captação dos recursos materiais necessários às campanhas eleitorais que são cada vez mais dispendiosas. Diante da inexistência dessas condições, são criados partidos que são máquinas políticas sob o comando pessoal de lideranças políticas, cujas relações de confiança estão baseadas e dependem de laços familiares ou laços afetivos de lealdade e gratidão para assegurar o segredo imprescindível na relação com as fontes de financiamento das campanhas e na ocupação de cargos e distribuição de recursos políticos provenientes do exercício do poder.

O sistema político estadual apresenta sinais de mais um ciclo de renovação com o surgimento de novas lideranças, num processo que reproduz a lógica clânico-oligárquico dominante. Assim, destaca-se o fenômeno do "filhotis- 
mo" político com o advento na cena política de uma nova geração de herdeiros familiares dos diversos grupos político-partidários. Esse processo é conduzido pelas atuais principais lideranças estaduais que já foram, quase em sua totalidade, frutos dessa renovação clânico-oligárquica algumas décadas atrás. Os principais grupos político-partidários cuidam agora de assegurar a iniciação política de seus descendentes que irão dar continuidade aos respectivos interesses políticos.

Em 2002, Wilma de Faria elegeu sua filha, Márcia Maia, para seu primeiro mandato como deputada estadual. Esse processo se intensificou em 2006 com a eleição do deputado federal Felipe Maia, filho de José Agripino Maia (DEM), do deputado federal Fábio Faria, filho do atual vice-governador Robinson Faria (PSD) e do deputado estadual Walter Alves, filho de Garibaldi Alves Filho (PMDB).

A renovação clânico-oligárquica ganhou maior densidade pela relevância dos cargos conquistados, com a eleição de Rosalba Ciarlini Rosado (DEM), ex-prefeita de Mossoró, como senadora em 2006 e governadora eleita em 2010.

Isso ocorreu como parte do contexto geral paradoxal em que o declínio nacional do DEM foi acompanhado da recuperação da liderança de José Agripino no Rio Grande do Norte, que adotou uma estratégia vitoriosa nas eleições majoritárias em 2006, quando elegeu Rosalba Ciarlini Rosado como senadora em disputa com o então senador Fernando Bezerra (PTB); em 2008, com a eleição de Micarla de Sousa (PV) como prefeita de Natal, com a derrota de Fátima Bezerra (PT), apoiada por Wil- ma de Faria, de Garibaldi Alves Filho e Henrique Alves; e em 2010 com a eleição de Rosalba Ciarlini Rosado (DEM) como governadora do Rio Grande do Norte e sua reeleição para uma das vagas em disputa para o senado.

\section{ASCENSÃO E DECLÍNIO DA GOVERNA- DORA ROSALBA CIARLINI}

A transformação da liderança regional de Rosalba Ciarlini Rosado em liderança estadual foi o resultado de um longo trabalho de construção da sua imagem pública. Médica pediatra, casada com o ex-deputado estadual Carlos Augusto Rosado, filho do ex-governador Dix-Sept Rosado, um dos principais representantes da família Rosado, que domina a política mossoroense a partir da metade do século XX, ingressou na política sendo eleita três vezes como prefeita de Mossoró (1988, 1996 e 2000). Adotou como marca política o nome de Rosalba Ciarlini, conveniente e aparentemente desvinculada dos grupos oligárquicos. Tornou-se uma liderança estadual contrariando uma tendência que caracteriza a política potiguar. Em geral, as lideranças estaduais surgem e se consolidam a partir da projeção de uma liderança política que tem origem em Natal, capital do Estado e principal colégio eleitoral.

Rosalba Ciarlini firmou sua liderança na principal cidade do interior como uma prefeita que, em três mandatos, transformou e modernizou a infraestrutura urbana de Mossoró. O grande crescimento econômico-social da cidade foi atribuído unilateralmente à competência de Rosalba como gestora, omitindo-se o substancial aumento da arrecadação municipal 
oriundo das atividades desenvolvidas pela Petrobras e as empresas que se fixaram em Mossoró para dar suporte técnico às crescentes demandas do setor petrolífero na região. É nesse contexto que a cidade despontou como centro regional de médio porte, que se sobressaiu por expressivas melhorias urbanas e exitosas políticas públicas, com intenso trabalho de marketing político na área cultural. Essa foi a base para a construção da sua imagem pública de administradora competente que foi difundida por toda a sociedade norte-rio-grandense.

Esse fenômeno ganhou expressão política na campanha eleitoral para o senado em 2006, quando Rosalba Ciarlini enfrentou e venceu, ao mesmo tempo, Fernando Bezerra, então senador e líder do governo Lula no Senado, e o ex-governador e senador Geraldo Melo. Numa campanha surpreendente ganhou a vaga senatorial e derrotou Fernando Bezerra, que iniciou a campanha como favorito. Rosalba Ciarlini (PFL) obteve 44,18\% \% dos votos; Fernando Bezerra (PTB), 43,42\% dos votos; e Geraldo Melo (PSDB), 10,64\% dos votos. Isso aconteceu também em Natal: Rosalba Ciarlini conseguiu 41,99\% dos votos e derrotou Fernando Freire, apoiado por Wilma de Faria, com $40,28 \%$ dos votos, e Geraldo Melo, que recebeu $12,98 \%$ dos votos dos eleitores natalenses (TSE, 2006).

Rosalba Ciarlini consolidou sua liderança estadual nas eleições municipais de 2008, quando teve destacada atuação política ao participar ativamente da campanha eleitoral em cidades de todas as regióes do Estado. Pela importância estratégica, todavia, concentrou sua atuação nos principais colégios eleitorais. Teve papel de relevo na vitória de Micarla de Sou- za à Prefeitura de Natal, consolidando sua imagem pública junto ao eleitorado natalense.

O ciclo de ascensão político-eleitoral de Ciarlini se completou com o êxito nas eleições 2010. Ao concorrer com o então governador Iberê Ferreira (que havia sido vice de Wilma de Faria e assumido o cargo com a renúncia desta para se candidatar ao Senado) e o ex-prefeito de Natal, Carlos Eduardo Alves, Rosalba venceu já no primeiro turno do pleito, obtendo $52,5 \%$ de votos (contra 36,3\% de Iberê e 10,4\% de Carlos Eduardo).

O consórcio político que levou Rosalba Ciarlini ao êxito eleitoral em 2010 foi marcado pela continuidade do acordo político entre Garibaldi Alves e José Agripino que, por extensão, se constituíram nos principais cabos eleitorais da então senadora. Há de se notar, contudo, que somente José Agripino fez parte da chapa majoritária encabeçada por Rosalba. O PMDB do grupo Alves lançou, com vistas a acomodar os interesses conflitantes em seu interior, uma chapa majoritária própria, capitaneada pela candidatura ao senado de Garibaldi.

Com tal artifício, Henrique Alves se viu liberado para apoiar Iberê ao governo e Wilma ao senado. Ademais, o PMDB também atraiu o PR, do deputado João Maia, e o PV, da então prefeita de Natal, Micarla de Souza, para uma coligação a deputado federal, que possibilitou a reeleição de Henrique Alves e João Maia e a eleição de Paulo Wagner (PV) para a Câmara Federal.

Rosalba também contou com o decisivo apoio do então presidente da Assembleia Legislativa do RN, Robinson Faria, que foi candidato a vice-governador em sua chapa. Robinson, 
que apoiou Wilma de Faria durante boa parte de seus dois mandatos como governadora, migrou para a oposição quando ficou definida a candidatura de Iberê Ferreira ao governo em 2010. A migração de Robinson e seus liderados (1 deputado federal, seu filho Fábio Farias, 4 deputados estaduais e vários prefeitos no interior do estado) foi a peça final no quebra-cabeça que levou Rosalba ao governo do Estado.

O outro lado da moeda na ascensão político-eleitoral de Rosalba Ciarlini e associados na eleição de 2010 foi o consequente declínio do grupo liderado por Wilma de Faria. Além da derrota de seu candidato ao governo, a própria Wilma sofreu um revés eleitoral (651.358 votos) em sua candidatura ao senado, sendo derrotada justamente por seus dois principais adversários, Garibaldi Alves (1.042.272 votos) e José Agripino (958.891 votos).

A composição inicial da equipe de governo de Rosalba indicaria uma das principais características da atual gestão estadual. As principais secretarias foram ocupadas por antigos colaboradores de Rosalba na prefeitura de Mossoró. Essa tendência à provincianização do governo levou, a médio prazo, ao seu crescente isolamento em relação às forças políticas e sociais que poderiam dar sustentação ao governo Rosalba. A paralisia administrativa e o isolamento político tem sido a marca do governo Rosalba nesses quase três anos do seu mandato.

A coalização de forças políticas que foi formada para a eleição de Rosalba começou a se desfazer, em outubro de 2011, antes de completar um ano do governo, com a crise política envolvendo o vice-governador Robson Faria e o ex-deputado estadual Carlos Augusto Ro- sado, marido da governadora, que provocou o pedido de exoneração do advogado Paulo de Tarso, chefe de gabinete, que era até então um dos principais assessores do governo. A partir daí, o vice-governador rompeu com a governadora e passou a fazer oposição ao governo.

Naquele episódio, a sociedade norte -rio-grandense tomou conhecimento de fatos graves que abalaram a autoridade da governadora Rosalba na condução do governo. As notícias veiculadas na imprensa informavam que o centro de decisão do governo estadual era ocupado por Carlos Augusto Rosado, marido da governadora.

Ao longo do tempo, o governo Rosalba não conseguiu mostrar que era capaz de implementar as políticas públicas prometidas durante a campanha eleitoral. Ficou paralisado em suas ações administrativas. Com isso, o discurso que marcou o início da gestão, que atribuía todas as dificuldades administrativas às dificuldades orçamentárias herdadas do governo anterior de Iberê Ferreira de Souza e Wilma de Faria, perdeu sua capacidade de convencer a sociedade sobre a fragilidade e a ineficiência no desempenho do novo governo.

A crise administrativa e financeira do governo Rosalba atingiu seu ápice com a impossibilidade do governo honrar seus compromissos dos repasses previstos constitucionalmente dos recursos orçamentários para o Poder Legislativo e o Poder Judiciário. Apesar do aumento da arrecadação de impostos, o governo estadual propôs a redução do percentual a ser repassado ao Legislativo e ao Judiciário. Além disso, como há muito não acontecia na administração pública estadual, o governo Rosalba 
atrasou o pagamento da folha salarial dos servidores públicos estaduais.

O PMDB, que participou do governo desde o início, se distancia do governo Rosalba e anunciou que terá candidato próprio nas eleições de 2014.

Enquanto isso, o senador José Agripino, presidente do DEM, declarou que o principal objetivo estratégico do partido não seria a reeleição da governadora Rosalba, mas a preservação eleitoral da sua bancada federal no Rio Grande do Norte. O seu objetivo é assegurar a reeleição do seu filho, o deputado federal Felipe Maia (DEM). Para tanto, começam a ser estabelecidos os primeiros entendimentos entre José Agripino e Garibaldi Filho. O objetivo é manter a aliança político-eleitoral entre ambos, traduzindo-se numa coligação partidária que conte com a participação do PMDB e do DEM em 2014.

O resultado foi o desgaste ${ }^{16}$ crescente frente à opinião pública e a consequente desaprovação popular, como tem revelado recentes pesquisas de opinião realizadas pela Consult Pesquisa e pelo Instituto Índice Pesquisa, que são institutos de pesquisa locais. Em junho de 2013, o Instituto Índice Pesquisa avaliou a aprovação do governo Rosalba: é desaprovado por 70,1\% da população - sendo $17,9 \%$ de regular negativo, ruim de 20,7\% e péssimo de 31,5\% (Vidal, 2013). E em agosto de 2013, a Consult Pesquisa avaliou o governo Rosalba: apenas 11,53\% aprovam, 83,35\% desaprovam e 5,12\% não têm opinião formada (Dantas, 2013).

\section{ELEIÇÕES AO GOVERNO DO RIO GRAN- DE DO NORTE: OBSERVANDO O PADRÃO BIPOLAR DE DISPUTA}

No plano eleitoral, a movimentação dos três principais grupos clânico-oligárquicos, em associação com os grupos alternativos e auxiliares, tem impactos diferenciados ao longo do tempo. Observando-se as disputas para o governo do estado no pós-redemocratização, é possível destacar três momentos distintos. Na década de 1990, a polarização entre Alves e Maias, advinda dos tempos de regime militar, é a tônica central. As eleições de 2002 marcam uma virada no padrão, com a ascensão de Wilma de Faria ao executivo estadual e consequente derrota dos candidatos referendados pelos grupos que antes monopolizavam a cena. Em 2006 e 2010, o embate passa a ser entre o campo liderado por Wilma e o consórcio político resultante da união entre Alves e Maia. De forma semelhante ao que ocorre nas eleições presidenciais, polarizadas por blocos políticos liderados pelo PT e pelo PSDB, as eleições para o governo estadual baseiam-se numa lógica dual de disputa.

A despeito das recorrentes avaliações de fragmentação do quadro partidário brasileiro, estudos recentes sobre o assunto demonstram que, em se tratando de eleições para o executivo, os padrões de disputa tendem a envolver uma seleção restrita de postulantes. Assim, especificamente no caso das eleições presidenciais e para os governos dos estados, o número de partidos em competição é reduzido e tende a se estruturar na oposição entre dois grandes grupos. Ademais, em larga medida, as coligações e

16 Nos debates parlamentares da Assembléia Legislativa, começa a ser cogitada a proposta de um impeachment da governadora Rosalba Ciarlini. 
arranjos políticos presentes nas primeiras tendem a influenciar a composição das segundas, mesmo que nelas exista um maior espaço para acomodação de interesses locais diversos da lógica nacional (Limongi e Cortez, 2010; Meneguello, 2011). Em sintonia com tais tendências, nas décadas de 1990 e 2000, as eleições para o governo do estado do Rio Grande do Norte envolveram um número restrito de concorrentes, recaindo, no mais das vezes, em um padrão bipolar de disputa.

É o que se pode visualizar através do Número de Partidos Efetivos $(\mathrm{Ne})^{17}$ das eleições para o governo do estado entre 1990 e 2010:

\section{Tabela 1 - Número Efetivo de Partidos por ELEIÇÃo - Governo RN - 1990-2010}

\begin{tabular}{ccc}
\hline \hline Eleição & Candidatos & $\mathrm{Ne}$ \\
1990 & 4 & 2,51 \\
1994 & 4 & 2,32 \\
1998 & 6 & 2,34 \\
2002 & 7 & 3,46 \\
2006 & 7 & 2,07 \\
2010 & 5 & 2,39 \\
\hline
\end{tabular}

Fonte: FERREIRA, BATISTA, STABILE (2008); TSE (elaboração própria)

No período considerado, embora o número de candidatos concorrentes tenha apresentado uma média de 5,5, o índice relativo à quantidade efetiva de partidos sempre esteve em torno de 2 (numa média de 2,51). Isto é, excetuando-se a eleição de 2002, tais dados corroboram a avaliação de um padrão de compe- tição baseado no confronto entre dois candidatos competitivos por pleito. A primeira eleição dos anos 2000 apresenta um Número de Partidos Efetivos fora da curva justamente porque há uma mudança na configuração dos grupos em disputa, com a ascensão de Wilma de Faria ao governo. Neste caso, torna-se importante salientar, a candidata do PSB se impôs à polarização anterior, mesmo com as candidaturas das famílias Alves e Maia postas (o vice-governador Fernando Freire, PPB, e o senador Fernando Bezerra, PTB, respectivamente).

O padrão polarizado e restrito das disputas ao executivo diferencia-se daquele encontrado para a Assembleia Legislativa. Por um lado, o Número de Partidos Efetivos para o legislativo no período foi maior (numa média de 6,46 entre 1990 e 2006, conforme estudo de Ferreira, Batista e Stabile, 2008, p. 443), demonstrado uma abertura à pluralidade. Por outro, embora tal pluralidade possa ser encontrada, a influência do executivo também se fez presente, restringindo os partidos em disputa em determinados pleitos. É o que se pode depreender da comparação entre a votação obtida pelas coligações vencedoras ao governo e seus representantes na casa legislativa estadual. Entre 1994 e 2010, quando se tratou da primeira eleição de um(a) dado(a) candidato(a) ao governo (Garibaldi Alves em 1994, Wilma de Faria em 2002 e Rosalba Ciarlini, em 2010), a tendência foi a de que suas respectivas coligações ao legislativo obtivessem uma votação menor, conforme mostra a tabela 2 (baseada em estudo de Rachel Meneguello, 2011). No sentido oposto, quando o(a) governador(a) foi reeleito(a) (Ga-

17 Calculado a partir da divisão por 1 do somatório dos quadrados da proporção de votos ou cadeiras obtidos pelos partidos. Para mais informações, ver Laakso e Taagepera (1979). 
ribaldi em 1998 e Wilma em 2006), os números mudaram, levando a uma maior volume de votação de seus apoiadores legislativos.

TABela 2 - Votação dos CANDidatos Eleitos AO GOVERNO DO RN E DE SUAS RESPECTIVAS COLIGAÇÕES PARA A Assembleia Legislativa (1994-2010)

\begin{tabular}{|c|c|c|c|}
\hline Eleição & $\begin{array}{l}\text { Candidato(a) } \\
\text { Eleito(a) }\end{array}$ & $\begin{array}{l}\text { Votos Válidos } \\
\text { Eleito(a) } \\
\left(1^{\circ} \mathrm{T} \%\right)\end{array}$ & $\begin{array}{l}\text { Coligação Ass. } \\
\text { Legislativa (\%) }\end{array}$ \\
\hline 1994 & $\begin{array}{l}\text { Garibaldi Alves } \\
\text { (PMDB) }\end{array}$ & 52,7 & 33,3 \\
\hline 1998 & $\begin{array}{l}\text { Garibaldi Alves } \\
\text { (PMDB) }\end{array}$ & 50,2 & 50 \\
\hline 2002 & $\begin{array}{l}\text { Wilma de Faria } \\
\text { (PSB) }\end{array}$ & 37,6 & 8,3 \\
\hline 2006 & $\begin{array}{l}\text { Wilma de Faria } \\
\text { (PSB) }\end{array}$ & 49,6 & 50 \\
\hline 2010 & $\begin{array}{l}\text { Rosalba Ciarlini } \\
\text { (DEM) }\end{array}$ & 52,5 & 29,1 \\
\hline
\end{tabular}

Fonte: Meneguello, 2011, pp. 24-29.

Embora ocorra uma maior quantidade de partidos em disputa para a Assembleia Legislativa, o "governismo" termina por prevalecer na dinâmica parlamentar (ABRUCIO, 1998), fazendo com que adversários do(a) governador(a) na campanha eleitoral sejam convertidos em base de apoio governamental no transcorrer do mandato. Esse fenômeno fica muito evidente nos números obtidos por Wilma de Faria e sua base de apoio. Em 2002, os candidatos da sua coligação partidária obtiveram apenas $8,3 \%$ dos votos válidos. Na sua reeleição, em 2006, o número de candidatos eleitos por sua coligação partidária elevou-se para 50\% em 2006.

Além dos dados acima, também são representativos do padrão bipolar de disputa ao governo do estado do RN a fração de votos obtida pelos grupos tradicionais e os índices de volatilidade eleitoral. A tabela 3 expõe os percentuais alcançados pelos candidatos lançados pelos três grupos aqui analisados no período compreendido entre 1994 e 2010. Em todas as eleições da série, a parcela de votos válidos arregimentados por eles é muito larga e gira em torno dos $90 \%$. Nelas, os pleitos polarizados são aqueles que apresentam maiores índices (acima de 90\% em 1994 e 1998 e chegando aos $98,2 \%$ em 2006, todos em eleições com pelo menos quatro candidatos em disputa). Nas eleições mais fragmentadas, com quatro e três candidatos obtendo mais do que $10 \%$ dos votos (em 2002 e 2010, respectivamente), os postulantes ao governo chancelados pela associação entre Alves e Maia e pelo grupo liderado por Wilma de Faria agregam uma fatia menor, mais ainda bastante elevada, dos votos $(88,39 \%$ e $88,8 \%)$.

É válido salientar que, para o cálculo da proporção de votos obtidos pelos três grupos em questão, foram considerados somente os escores ou das lideranças dos mesmos ou dos candidatos por elas diretamente chancelados. O que exclui dos resultados agregados expostos na coluna "Total Grupos" as votações de Ruy Pereira, em 2002 (uma vez que o PT somente passou a apoiar Wilma de Faria no segundo turno daquele pleito), e Carlos Eduardo, em 2010 (posto que, formalmente, a ex-governadora apoiava o candidato de seu partido, Iberê Ferreira). Todavia, com vistas a calcular os índices de volatilidade eleitoral no período, é possível incorporar os percentuais obtidos por tais candidatos àqueles arregimentados pelos demais postulantes ao governo advindos dos mesmos grupos. 
Tabela 3 - VotaÇÃO dos(DAS) CANDIDATOS AO GOVERNO DO RN (1994-2010)

\begin{tabular}{|c|c|c|c|}
\hline Eleição & Candidatos(as) & $\begin{array}{c}\text { Votos Válidos } \\
\text { Polarização } \\
\left(1^{\circ} \text { T \% }\right)\end{array}$ & $\begin{array}{c}\text { Total } \\
\text { Grupos } \\
(\%)\end{array}$ \\
\hline \multirow{2}{*}{1994} & $\begin{array}{l}\text { Garibaldi Alves } \\
\text { (PMDB) }\end{array}$ & 52,7 & \multirow{2}{*}{91,4} \\
\hline & $\begin{array}{l}\text { Lavoisier Maia } \\
\text { (PDT) }\end{array}$ & 38,7 & \\
\hline \multirow{2}{*}{1998} & $\begin{array}{l}\text { Garibaldi Alves } \\
\text { (PMDB) }\end{array}$ & 50,2 & \multirow{2}{*}{91,56} \\
\hline & $\begin{array}{l}\text { José Agripino } \\
\text { (PFL) }\end{array}$ & 41,36 & \\
\hline \multirow{4}{*}{2002} & $\begin{array}{l}\text { Wilma de Faria } \\
\text { (PSB) }\end{array}$ & 37,6 & \multirow{4}{*}{88,39} \\
\hline & $\begin{array}{l}\text { Fernando Freire } \\
\text { (PPB) }\end{array}$ & 30,89 & \\
\hline & $\begin{array}{c}\text { Fernando Bezerra } \\
\text { (PTB) }\end{array}$ & 19,9 & \\
\hline & Ruy Pereira (PT) & 11,24 & \\
\hline \multirow{2}{*}{2006} & $\begin{array}{l}\text { Wilma de Faria } \\
\text { (PSB) }\end{array}$ & 49,6 & \multirow{2}{*}{98,2} \\
\hline & $\begin{array}{l}\text { Garibaldi Alves } \\
\text { (PMDB) }\end{array}$ & 48,6 & \\
\hline \multirow{3}{*}{2010} & $\begin{array}{l}\text { Rosalba Ciarlini } \\
\text { (DEM }\end{array}$ & 52,5 & \multirow{3}{*}{88,8} \\
\hline & $\begin{array}{l}\text { Iberê Ferreira } \\
\text { (PSB) }\end{array}$ & 36,3 & \\
\hline & $\begin{array}{l}\text { Carlos Eduardo } \\
\text { Alves (PDT) }\end{array}$ & 10,38 & \\
\hline
\end{tabular}

Fonte: TSE (elaboração própria)

Em geral, o índice de volatilidade eleitoral mede o grau de estabilidade da votação entre pares de eleições, a partir do cálculo da quantidade de votos ganhos ou perdidos entre partidos ou "blocos" políticos ${ }^{18}$. Quanto menor o índice, menor a fragmentação do sistema partidário em análise. Para o período em questão, foram calculados índices de volatilidade dos períodos 1994-1998, 2002-2006 e 20062010 (todos relativos aos primeiros turnos das diferentes eleições).

Cada par representa os diversos momentos da disputa política no estado. O primeiro demonstra que, nas duas disputas nas quais Garibaldi Alves derrotou seus contendores da família Maia, as votações variaram em 2,58. No segundo conjunto de eleições, representativo dos dois pleitos vencidos por Wilma de Faria, tal índice chega a mínimos $0,2^{19}$. Por fim, no último período, a volatilidade eleitoral obteve seu maior número na série, mas ainda apresentou um resultado baixíssimo, com 3,41. Por se tratar de um indicador que, teoricamente, pode variar entre 0 e 100, os números apresentados pelo índice de volatilidade eleitoral no Rio Grande do Norte foram ínfimos.

Isso significa que, nos pares de eleições considerados, os eleitores tenderam a manter suas escolhas restritas aos partidos e blocos considerados. Tomando-se em conjunto o reduzido número de partidos efetivos em disputa pelo governo, os baixos índices de volatilidade eleitoral e da elevada proporção de votos arregimentada pelos três grupos tradicionais estabelecidos na cena política norte-rio-grandense, pode-se ter a dimensão da sua capacidade de hege-

18 Nicolau explica como o índice é calculado: "The volatility index is calculated as follows: The percentage of votes (or seats) that a party received in an election is subtracted from the percentage of votes obtained by this same party in the preceding election; the difference indicates the change, and the $(-)$ or $(+)$ signs reveal the decline or growth of a party, respectively. The next step is to add the result of this operation (not considering the sign) and divide by two" (2011, p. 36). Como dito, o índice também pode ser calculado para blocos de partidos a partir do somatório das votações de seus partidos constitutivos.

19 Neste caso, os percentuais da socialista foram somados aos do candidato petista, em 2002, e comparados com a votação da mesma em 2006. Por seu turno, as votações de Fernando Freire e Fernando Bezerra foram comparadas com as de Garibaldi Alves em 2006. 
monizar a disputa política no estado. Em se tratando das eleições para o executivo estadual há, portanto, pouco espaço para candidaturas políticas que se organizem para além deles. Ademais, o padrão bipolar de disputa mostrou-se consolidado, mesmo que com atores diferentes.

\section{CONSIDERAÇÕES FINAIS}

A exemplo das corridas presidenciais brasileiras, baseadas no "duopólio" (LIMONGI E CORTEZ, 2010, p. 23) do PT e PSDB, as eleições para o governo do Rio Grande do Norte têm ocorrido através de disputas duais entre os três principais grupos políticos do estado, liderados pelas famílias Alves e Maia e pela ex-governadora Wilma de Farias. Ao longo do período que se estende da "abertura" política aos dias atuais, as relações entre tais conglomerados hegemônicos ocorrem com tensões internas recorrentes entre suas lideranças (seja entre Garibaldi e Henrique Alves, José Agripino e o casal Rosado, Wilma de Faria e Robson Faria) e processos pendulares de aproximação e afastamento entre os mesmos.

Nesse processo, alguns indícios relativos ao processo de formação e manutenção de tais grupos revelam tendências políticas que reverberam na atual conjuntura política do estado.

Pelo movimento das principais lideranças, há uma tendência na manutenção da aliança política entre os grupos Alves e Maia nas eleições de 2014. Atualmente, os rumos desse consórcio dependem dos desígnios do PMDB.
Esse maior protagonismo do PMDB dos Alves ocorre tanto devido ao declínio político do governo Ciarlini, quanto da maior proeminência dos seus líderes em âmbito nacional ${ }^{20}$. Como figuras-chave da aliança nacional entre PT e PMDB, Garibaldi e Henrique Alves passaram a disputar, em plano estadual, os legados dos governos Lula e Dilma, apesar de manter localmente a aliança com o DEM (adversário mais aguerrido dos governos petistas).

A apropriação dos feitos das administrações presidenciais petistas e seu espólio eleitoral tem sido uma das características do grupo de Wilma de Faria. Após a derrota fulminante em 2010, Wilma de Faria mantem-se na cena política como vice-prefeita de Carlos Eduardo em Natal. Na esteira da crise de popularidade de Rosalba Ciarlini, Wilma de Faria apresenta sinais de reabilitação e pode voltar a influir sobre o destino de lideranças auxiliares como Carlos Eduardo Alves e Robson Faria.

Mesmo com uma eventual mudança de atores, o quadro de polarização de forças políticas no Rio Grande do Norte tende a se reproduzir num futuro próximo.

Trabalho recebido em 20/09/2012 Aprovado para publicação em 15/12/2012

\section{REFERÊNCIAS BIBLIOGRÁFICAS}

ABRUCIO, Fernando Luiz. O ultrapresidencialismo Estadual. In: ANDRADE, Regis de Castro (Org.). Processo de Governo e no Estado:

20 Atualmente, Garibaldi Filho é o ministro da Previdência Social, desde o início do governo Dilma Rousseff, e Henrique Alves é o presidente da Câmara dos Deputados. 
uma análise a partir de São Paulo. São Paulo: EDUSP, 1998a.

COUTINHO, Carlos Nelson. As categorias de Gramsci e a realidade brasileira. Gramsci e a América Latina. Rio de Janeiro: Paz e Terra, 1988.

EVANGELISTA, João Emanuel. Os candidatos e a campanha eleitoral na televisão: as estratégias político-discursivas dos candidatos à prefeitura de Natal em 2004. In LEMENHE, Maria Auxiliadora e CARVALHO, Rejane Vasconcelos Accioly. Política, Cultura e Processos Eleitorais. Fortaleza: Fundação Konrad Adenauer, 2006 a.

EVANGELISTA, João Emanuel. As classes subalternas e o mundo da política: senso comum e bom senso na recepção e decodificação do HGPE nas eleições de 2004. GT mídia e eleições. I Compolítica. UFBA, 2006b.

DANTAS, Diógenes. Dona Wilma já lidera cenário com Garibaldi na disputa pelo governo. Disponível em http://nominuto.com/blogdodiogenes/bandconsult-dona-wilma-ja-lideracenario-com-garibaldi-na-disputa-pelo-governo/4457/. Acesso em 15 de novembro de 203.

FERREIRA, Denise Paiva; BATISTA, Carlos Marcos; STABILE, Max. A evolução do sistema partidário brasileiro: número de partidos e votação no plano subnacional 1982-2006. Opinião Pública. Campinas, v.14, n.2, 2008.

GRAMSCI, Antonio. Cadernos do Cárcere: O Risorgimento. Notas sobre a história da Itália. Volume 5. Rio de Janeiro: Civilização Brasileira, 2002.
LAAKSO, M. e TAAGEPERA, R. Effective Number of Parties: a measure with application to Western Europe. Comparative Political Studies, vol.12, nº1, 1979.

LIMONGI, F e CORTEZ, R. As eleições 2010 e o quadro partidário. Novos Estudos, 2010, n. 88 .

MENEGUELLO, Rachel. Las elecciones de 2010 y los rumbos del sistema de partidos brasileño. Política nacional, fragmentación y lógica de coaliciones. Disponível em: http://venus. ifch.unicamp.br/pos/cp/selecao/2011/las_elecciones_de_2010_y_los_rumbos_del_sistema_ de_partidos_brasile\%C3\%B1o.pdf. Acesso em 30 de dezembro de 2011.

NICOLAU, Jairo. Elections, Volatility, In: BERTRAND BADIE; BERG-SCHOLOSSER, Dirk; MORLINO, Leonardo. (Org.). International Encyclopedia of Political Science. Los Angeles: Sage, 2011, v. 4 , p. 35-38.

SANTOS, Wanderley Guilherme dos. A universalização da democracia. In BENEVIDES, Maria Victoria; KERCHE, Fábio; e VANNUCHI, Paulo (orgs.). Reforma Política e Cidadania. São Paulo: Editora Fundação Perseu Abramo, 2003.

VIANNA, Luiz Werneck. A revolução passiva: Iberismo e americanismo no Brasil. Rio de Janeiro: Revan, 1997.

VIDAL, Casciano. Pesquisa Índice revela aprovação de Carlos Eduardo e Dilma Rousseff e mostra Rosalba Ciarlini sem aprovação. Disponível em: http://www.cascianovidal.com.br/ pesquisa-indice-revela-aprovacao-de-carloseduardo-e-dilma-rousseff-e-mostra-rosalba-ciar- 
lini-sem-aprovacao/. Acesso em 15 de novembro de 203.

WEBER, Max. A Política como Vocação. In WEBER, Max. Ciência e Politica: duas vocações. 11a ed., São Paulo: Cultrix, 1999. 